This item was submitted to Loughborough's Research Repository by the author.

Items in Figshare are protected by copyright, with all rights reserved, unless otherwise indicated.

\title{
An improved experimental method for local clothing ventilation measurement
}

PLEASE CITE THE PUBLISHED VERSION

http://dx.doi.org/10.1016/j.ergon.2013.10.009

PUBLISHER

(c) Elsevier

VERSION

AM (Accepted Manuscript)

LICENCE

CC BY-NC-ND 4.0

\section{REPOSITORY RECORD}

Ke, Ying, Jun Li, and George Havenith. 2019. "An Improved Experimental Method for Local Clothing Ventilation Measurement”. figshare. https://hdl.handle.net/2134/13919. 
This item was submitted to Loughborough's Institutional Repository (https://dspace.lboro.ac.uk/) by the author and is made available under the following Creative Commons Licence conditions.

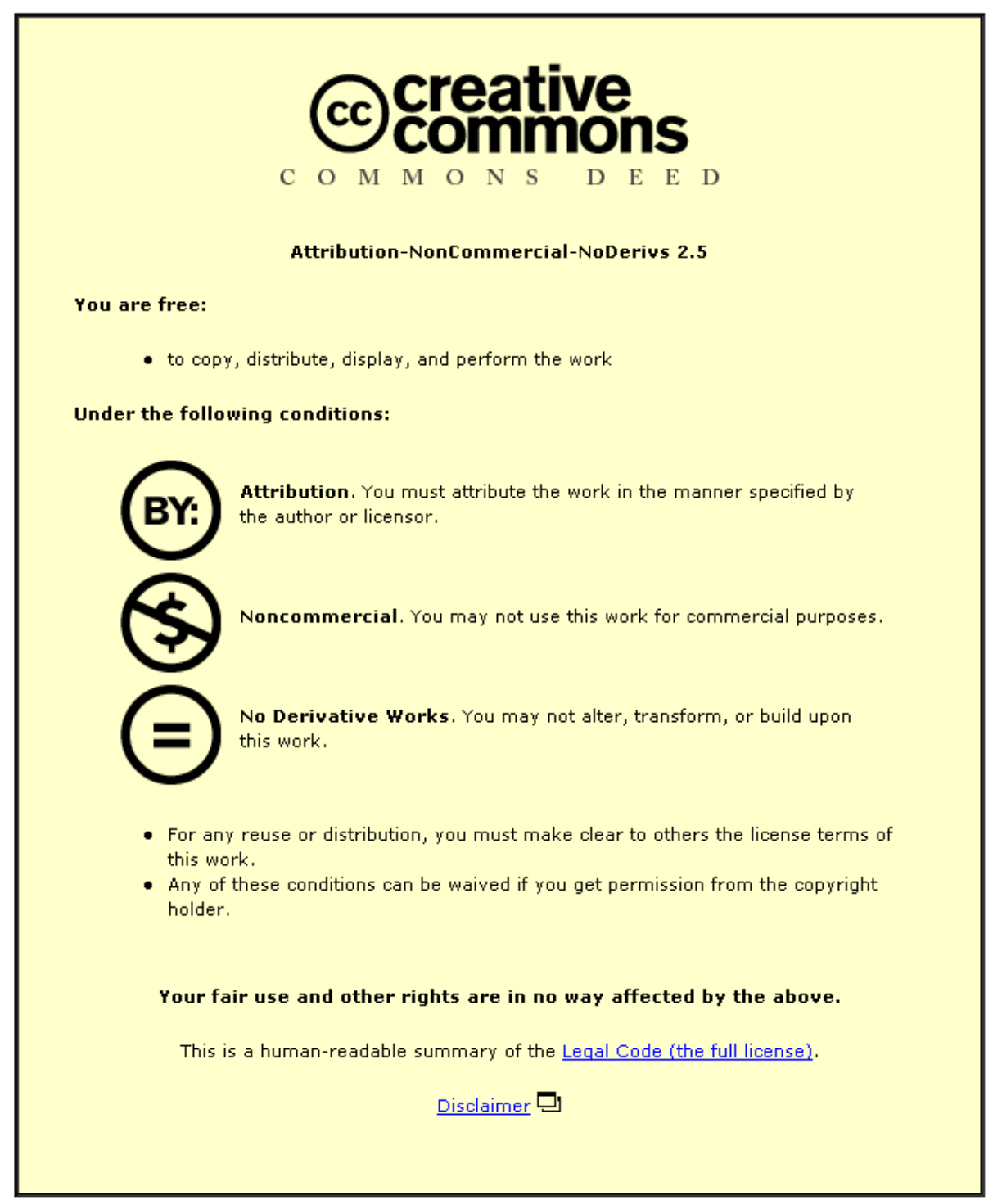

For the full text of this licence, please go to: http://creativecommons.org/licenses/by-nc-nd/2.5/ 
- $\quad$ Ke Y, Li J, Havenith G

International Journal of Industrial Ergonomics 44(1):75-81 Jan 2014 DOI

http://dx.doi.org/10.1016/j.ergon.2013.10.009

\title{
An improved experimental method for local clothing ventilation measurement
}

\author{
Ying Ke ${ }^{\mathrm{a}, \mathrm{b}}$, Jun $\mathbf{L i}^{\mathrm{a} \mathrm{b}^{*}}$ and George Havenith ${ }^{\mathrm{c}}$ \\ ${ }^{a}$ Protective Clothing Research Center, Fashion Institute, Donghua University, Shanghai 200051, \\ China \\ ${ }^{\mathrm{b}}$ Key Laboratory of Clothing Design \& Technology (Donghua University), Ministry of Education, \\ Shanghai 200051, China \\ ${ }^{\mathrm{c}}$ Environmental Ergonomics Research Center, Loughborough University, Loughborough LE11 \\ 5NG, UK
}

*Corresponding author. Fashion Institute, Donghua University, Shanghai 200051, China.

E-mail: lijun@dhu.edu.cn (J. Li)

Tel: +86 021-62378323

\begin{abstract}
A clothing local ventilation measuring device based on the Lotens-Havenith steady state tracer gas method was developed and an improved experimental method for understanding local ventilation mechanisms was proposed. The local ventilation system can measure the arm, chest and back ventilation rates at the same time. Local ventilation mechanisms of an impermeable garment at two activities (static, walking) and two wind speeds(no wind, $1.2 \mathrm{~m} / \mathrm{s}$ ) were studied, with a focus on determining the pathways of ventilation through the different garment openings. The results showed that local ventilation rates of chest, back and arm varied considerably over locations and conditions. As expected, ventilation rates were highest for all locations at walking with wind conditions. Ventilation mechanism changed at different walking and wind conditions. The main air exchange pathway for all locations was through the garment bottom. Wind had a greater impact on clothing local ventilation than walking.

Relevance to industry: Clothing ventilation impacts worker's thermal comfort and safety directly both in the cold and heat. The new clothing local ventilation measuring device developed in this paper can measure both clothing local and whole ventilation. It can also help us to separate the different pathways for heat loss through clothing.
\end{abstract}

Key words: Local ventilation; Tracer gas method; Ventilation mechanism 


\section{Introduction}

Clothing microclimate ventilation is an effective way for the human body to lose heat. Especially for workers in the hot dry conditions, it is an efficient cooling avenue. Over the years, three methods have been developed to measure clothing ventilation: one by Crockford (CR)-unsteady state method(Crockford.Gw et al., 1972), one by Lotens and Havenith (LH)-steady state method(Lotens and Havenith, 1988) and one by Reischl(Reischl and Stransky, 1980). The first two methods are used to measure whole garment ventilation, while the third method is intended for local ventilation at a single point only. Havenith and Zhang(Havenith et al., 2010) compared the first two methods on reproducibility, validity, sensitivity and applicability for the determination of microclimate ventilation and vapor resistance. Both methods worked well. However, Crockford's method requires the measurement of the clothing microclimate volume, which is complicated and error prone(Havenith et al., 2010).The 3D scanning method is the most accurate to measure microclimate volume(Lee et al., 2007). But the equipment is costly and laborious 'repair' work has to be done to the scans to get a closed model. So the LH method(Lotens and Havenith, 1988) is easier used in research and industry(Havenith et al., 1990a; Satsumoto and Havenith, 2010).

The air space between the human body and the garment is a main factor influencing ventilation rates. But this always changes according to different activities and locations(Ghaddar et al., 2003).Therefore the clothing microclimates (air gap thickness and microclimate volume) of local regions are always different(Zhang et al., 2010). In addition local sweat rates are also different(Havenith et al., 2008; Smith and Havenith, 2011), interacting with local ventilation rates to deliver cooling(Ueda et al., 2006; Havenith et al., 2003; Ueda and Havenith, 2002; Ueda et al., 2005). Therefore local ventilation rates need to be evaluated separately to enable designers to optimize clothing design for improved thermal comfort. Recently two local ventilation systems have been developed. One was built by Satsumoto and Havenith(SH)(Satsumoto and Havenith, 2010), and the other was developed by Ueda et al. (UI)(Ueda et al., 2006). SH used the LH steady state method(Havenith et al., 1990a; Havenith et al., 1990b) to evaluate four regions' local ventilation rates of diapers. But the method needed to control the inlet and outlet flow rate precisely the same which can be difficult technically. In addition, the SH system can only measure one part's ventilation at one time, which wastes trace gas and extends testing time. UI used the CR unsteady state method to evaluate chest, back and upper arm ventilation separately, approximating clothing microclimate using a cylinder model(Lotens and Havenith, 1991), thereby increasing potential uncertainty and error. Satsumoto also evaluated the local ventilation in diapers using the CR unsteady state method before(Y. et al., 2008). They demonstrated that the steady state method was better than the transient method(Satsumoto and Havenith, 2010).

Air exchange between a specific garment location and the environment includes three parts: 1:air exchange between local body parts' microclimates, 2: air exchange through the fabric with the environment and 3: through garment apertures with the environment. Of these, only air exchange between the microclimate and the environment directly helps heat loss, which can be called effective ventilation. The air exchange between different clothing sections may not be effective as the air coming in from other sections may already be heated and have 
absorbed moisture there. Therefore it is of high importance to understand the local ventilation mechanism as this may give some suggestions to garment apertures design especially for functional garments that can only have one or two apertures.

In the present study, a local clothing ventilation system was developed based on the LH steady state tracer gas method to measure local microclimate ventilation rates in different locations. Using this setup, a study was designed to better understand local ventilation mechanism at two activities (stand, walking) and two wind conditions(no wind, $1.2 \mathrm{~m} / \mathrm{s}$ ), giving specific attention to air exchange via the different apertures of the clothing.

\section{Method}

We divided the upper body garment into 4 areas-right arm, left arm, chest and back. The upper body has approximately vertical symmetry. Therefore for vertical symmetry garments only local ventilation rates of the right arm(or left arm),the chest and the back need to be measured.

\subsection{Local ventilation rates measuring system}

Figure1 shows the schematic diagram of the local ventilation system for one location. A steady state tracer gas method based on the LH principle was used(Lotens and Havenith, 1988; Havenith et al., 2010). Argon was chosen as tracer gas, as it constitutes a compromise between similarity with water vapor in molecular diameter, low background concentration, lack of absorption and safety considerations(Havenith et al., 1990c; Lotens and Havenith, 1988). But it is still need to mention that the diffusion constants of Argon and water vapor are different. The respective diffusion constant of Argon relates to that of water vapor in air is 0.7(Havenith et al., 2010). In addition, the absorption capability of the two gases also differed. The main tracer gas concentration measuring device is a mass spectrometer (Spectra, Crewe, UK).

Argon was premixed with air before going into clothing microclimate. The pump connected to garment outlet flow (sampling tubing)was for circulation of air through the system, back into the garment after enriching it with pure Argon. A second, smaller pump connected to the mass spectrometer was for sampling. All sampling connections to the mass spectrometer were placed on the positive pressure side of the main circulation pump to reduce pressure differences in the sampling line. This aimed to reduce the impacts of pressure differences in the system on mass spectrometer values, as this is very sensitive to pressure differences.

One improvement of the system compared to Havenith et al.'s(Lotens and Havenith, 1988; Havenith et al., 2010)is that all sampling flow was returned to the main flow after sampling (rather than being discarded), which decreases the impacts of the sampling process on the testing precision. Due to this improvement, there was no need to strictly limit the sampling flow rate theoretically (For Havenith et al.'s system(Havenith et al., 2010) the whole garment sampling flow rate is controlled below $1 \mathrm{l} / \mathrm{min}$ compared to a main flow rate of $20 \mathrm{l} / \mathrm{min}$, but due to the lower measurement volumes of the local zones compared to a full body system, the total flows needed to be reduced $(<2 \mathrm{l} / \mathrm{min}$ per area) to reduce the impact of the measurement flow on the ventilation process itself, while the sampling flow rate could not be reduced to a similar ratio to maintain stability and speed).

Argon distribution and sampling took place via tubing systems. Both systems were branched 
with same diameter tubes(arm-4 tubes, chest and back-6 tubes) for even Argon distribution and sampling. These tubes were sealed and perforated every $100 \mathrm{~mm}$ by orthogonal pairs of $1 \mathrm{~mm}$ i.d. holes. Tubes supplying to and sampling from the arms were not perforated for the first 170mm (The distance from about the waist to the shoulder) to avoid excessive Argon distribution across chest or back. The distance of the tubes from the shoulder to the end was about $60 \mathrm{~cm}$.

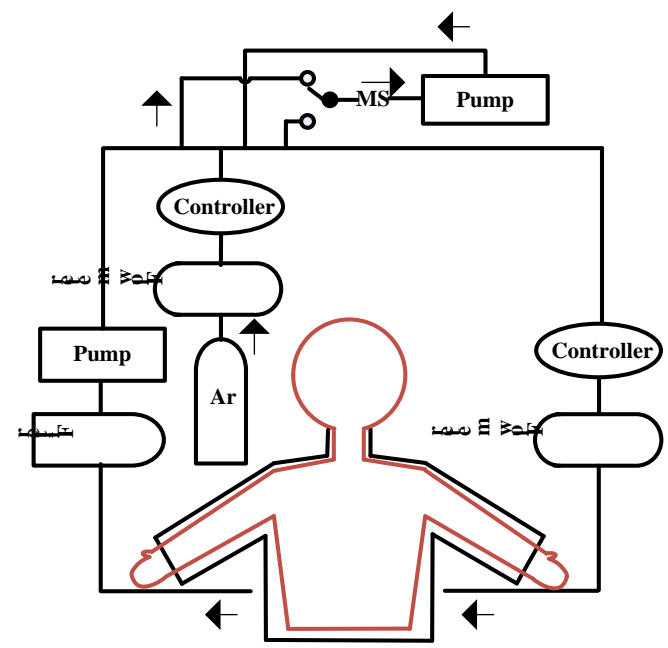

Fig. 1 Schematic diagram of the local ventilation system for one location

\subsection{Ventilation computational methods}

For each location $i$, microclimate ventilation rate ( $\left(\right.$ Vent $_{\mathrm{i}}$ ) is (Havenith et al., 2010; Havenith et al., 1990c):

Vent $_{i}=V_{i} \times\left(C_{\text {in }, i}-C_{\text {out }, i}\right) /\left(C_{\text {out }, i}-C_{\text {air }, i}\right)$

Where $i$ stands for different locations, from 1 to $4, \mathrm{~V}$ is the flow rate of local circulating system(l/min), $C_{\text {in }}$ is Argon concentration of the garment inlet flow(\%), $C_{\text {out }}$ is Argon concentration of the garment outlet flow(\%), $C_{a i r, i}$ is the Argon concentration of the atmosphere around the $\mathrm{i}^{\text {th }}$ clothed body(\%).

In addition, the system can also measure whole ventilation ( $\overline{V e n t})$ indirectly. That is: $\overline{\text { Vent }}=\sum_{\mathrm{i}=1}^{4}(\text { Circulating flow })_{i} \times\left(\overline{C_{\text {in }}}-\overline{C_{\text {out }}}\right) /\left(\overline{C_{\text {out }}}-\overline{C_{\text {air }}}\right)$

Where

$\overline{C_{i n}}=\sum_{i=1}^{4}\left(C_{i n} \times \text { Circulating flow }\right)_{i} / \sum_{i=1}^{4}(\text { Circulating flow })_{i}$

and 
$\overline{C_{\text {out }}}=\sum_{i=1}^{4}\left(C_{\text {out }} \times \text { Circulating flow }\right)_{i} / \sum_{i=1}^{4}(\text { Circulating flow })_{i}$

$\overline{\text { Vent }}$ is the average ventilation of the whole upper garment $(\mathrm{l} / \mathrm{min}), \overline{C_{i n}}$ is the average Argon concentration of the inflow into the garment(\%), $\overline{C_{\text {out }}}$ is the average Argon concentration in the clothing microclimate (\%), $\overline{C_{\text {air }}}$ is the average Argon concentration of air around clothed upper body (\%).

\section{Experimental}

\subsection{Testing specimen and apparatus}

In order to exclude air exchange through the fabric, air impermeable clothing was chosen(figure 3 and 4). Thus for impermeable clothing, the ventilation for each location then includes only two parts: air exchange between the clothing microclimate and the environment and air exchange between this location inside the clothing to other locations inside the clothing. Only the first part will optimally help heat loss(effective ventilation), as the second exchanges air that may already have absorbed heat and moisture in the other clothing section. In order to investigate these streams, we monitored ventilation changes by closing garment openings or connections between locations. In that case, we hypothesize that: First, upper garment is centerline symmetrical. Therefore we only need to analyze ventilation rates of one arm. Second, the ventilation of the right arm microclimate takes place through: right cuff, right arm, neck, bottom, left arm and left cuff. Ventilation of chest and back is through right cuff, right arm, neck, bottom, left arm and left cuff. Elastic bands with $1.5 \mathrm{~cm}$ width are used to close individual pathways for ventilation. Every closing band had even holes on it and a button at the end. The button was fixed to a certain hole for each aperture closing. Figure 2 illustrates details of the specific closing parts.

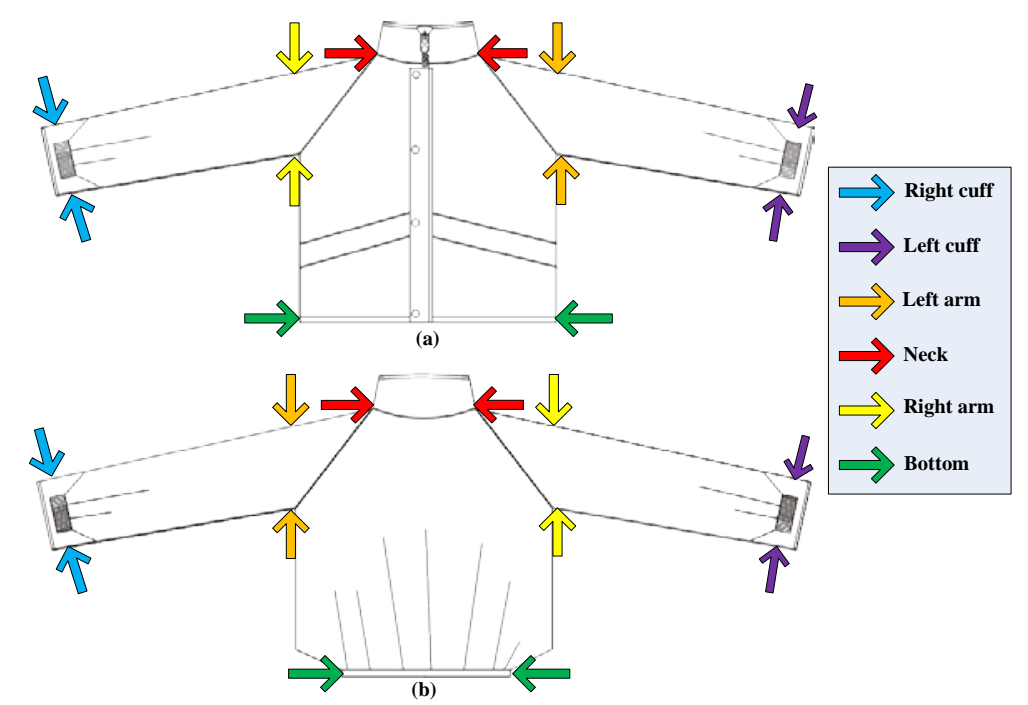

Fig. 2 Illustration of openings of experimental garment and locations where the openings were closed for testing. (a), front; (b), back.

An impermeable jacket with raglan sleeves was chosen as study object(figure 3). The jacket 
was two-layered and $100 \%$ polyester. The length, bust circumference, sleeve length and cuff around of the jacket were $72,124,64$ and $19 \mathrm{~cm}$, respectively. In the front, the fastener was a zipper that closed to the top of the collar. And a placket front was used to prevent air exchange through zipper. In the back, the garment bottom was tightened with elastic band. The sleeve linings had tight wrist cuffs. To estimate the effect of arms and legs movement(walking)on local ventilation, a walking thermal manikin(Newton, MTNW, Seattle) was used. The chest width, waist width and hip width of the manikin were 93,74 and $93 \mathrm{~cm}$, respectively. To study the effects of wind on local ventilation, a fan system was located about $1.5 \mathrm{~m}$ in front of manikin, as shown in figure 4.

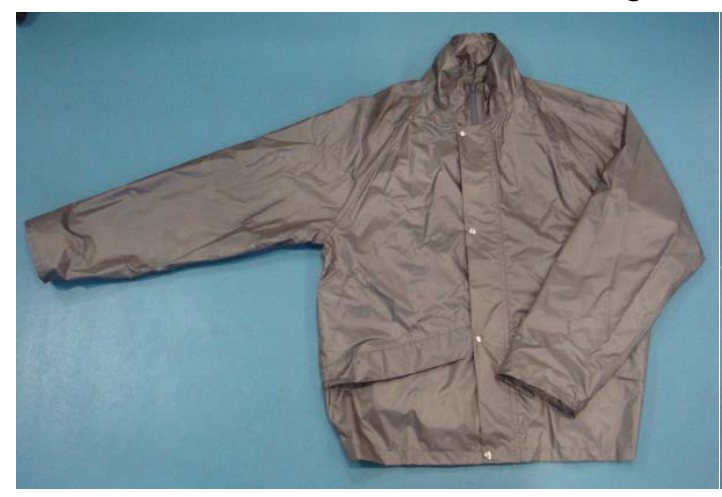

(a)

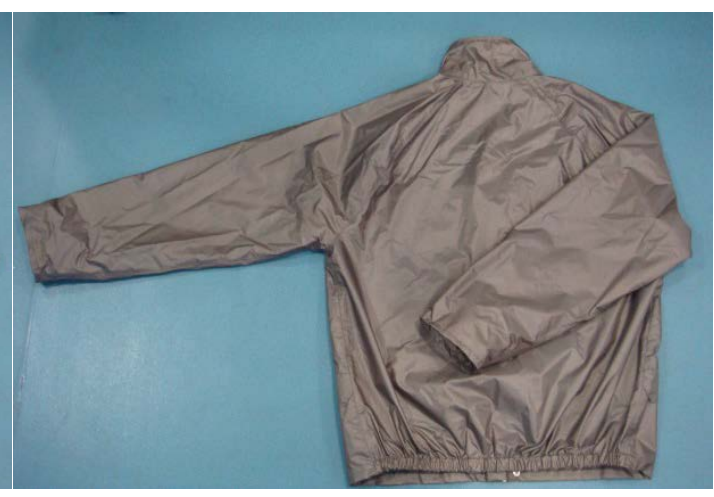

(b)

Fig. 3 Photograph of experimental jacket. (a), front; (b), back.

\subsection{Testing procedure}

The experiment was carried out at the Environmental Ergonomics Research Centre of Loughborough University Design School, in a chamber with air flow $<0.15 \mathrm{~m} / \mathrm{s}$. Firstly, pumps for system circulation of the three test locations were switched on. Then the Argon tank was switched on and the pure Argon flow rate going into the main flow was regulated to less than $0.15 \mathrm{l} / \mathrm{min}$. Then by switching five 3-way valves, the Argon concentrations of individual inlets and outlets were monitored until the whole system reached a steady state. Then we recorded the inlet and outlet Argon concentration for all locations one by one. The Argon concentration of the atmosphere of the local clothed body was measured for half an hour. Each test condition was repeated at least 4 times.

Two activities were tested: standing still and walking at $1.25 \mathrm{~m} / \mathrm{s}$. Two wind conditions were tested: no wind and $1.2 \mathrm{~m} / \mathrm{s}$. Therefore, overall 4 conditions were tested: standing without wind, standing with wind, walking without wind, walking with wind. 


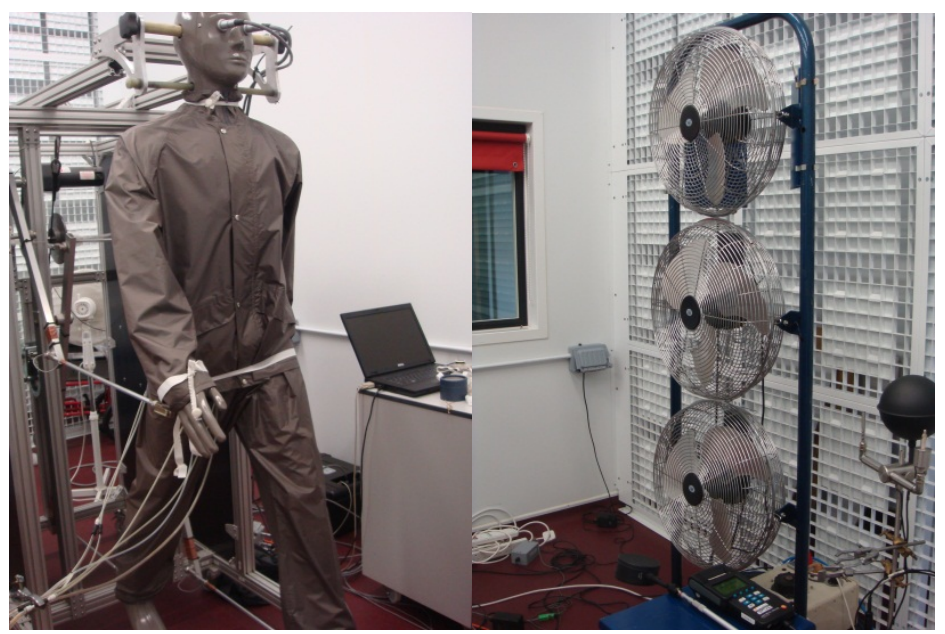

Fig. 4 The test setup of the manikin and the fans used for air movement. The left picture shows the neck and bottom opening closed.

\section{Results and discussion}

4.1 Local ventilation rates of right arm at different closing and conditions

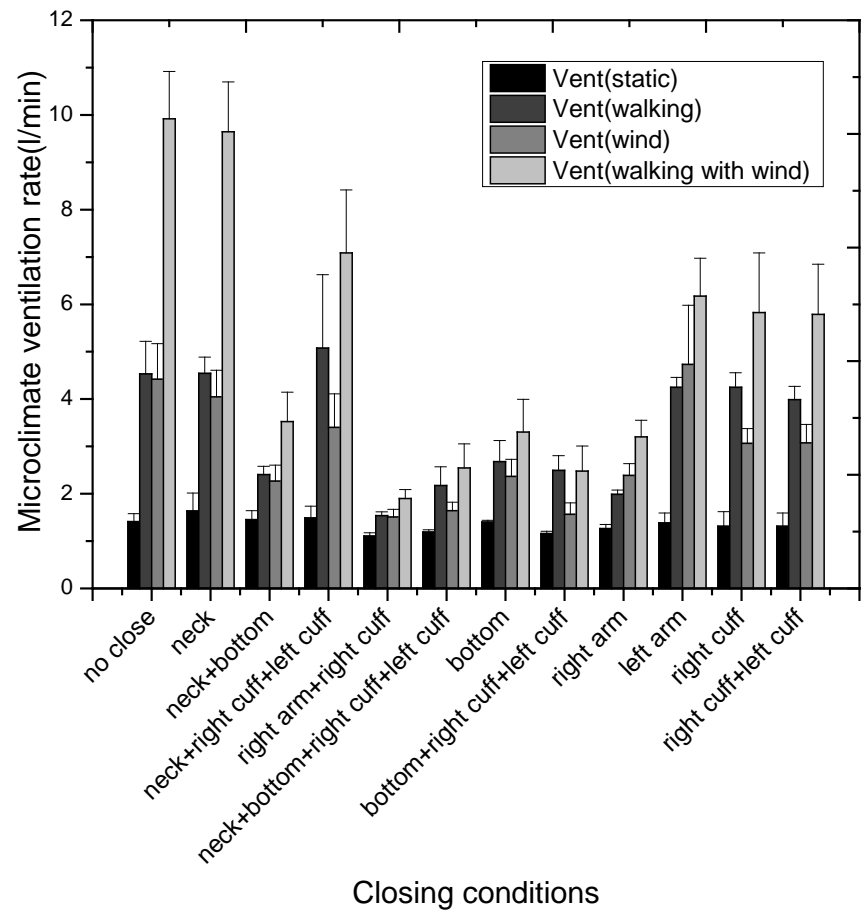

Fig. 5 Observed values of right arm ventilation with their standard deviation at different conditions of closing single or multiple openings. The horizontal axes subscripts indicate which of the openings were closed. 


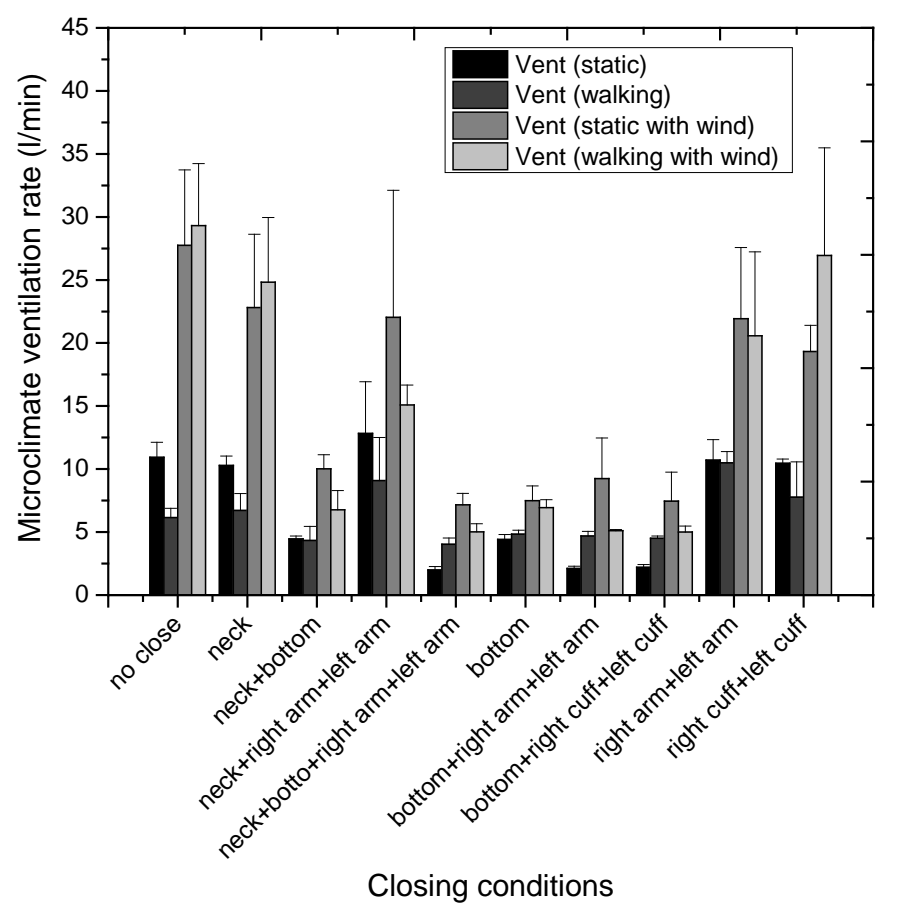

Fig. 6 Observed values of Chest ventilation with their standard deviation at different conditions of closing single or multiple openings. The horizontal axes subscripts indicate which of the openings were closed.

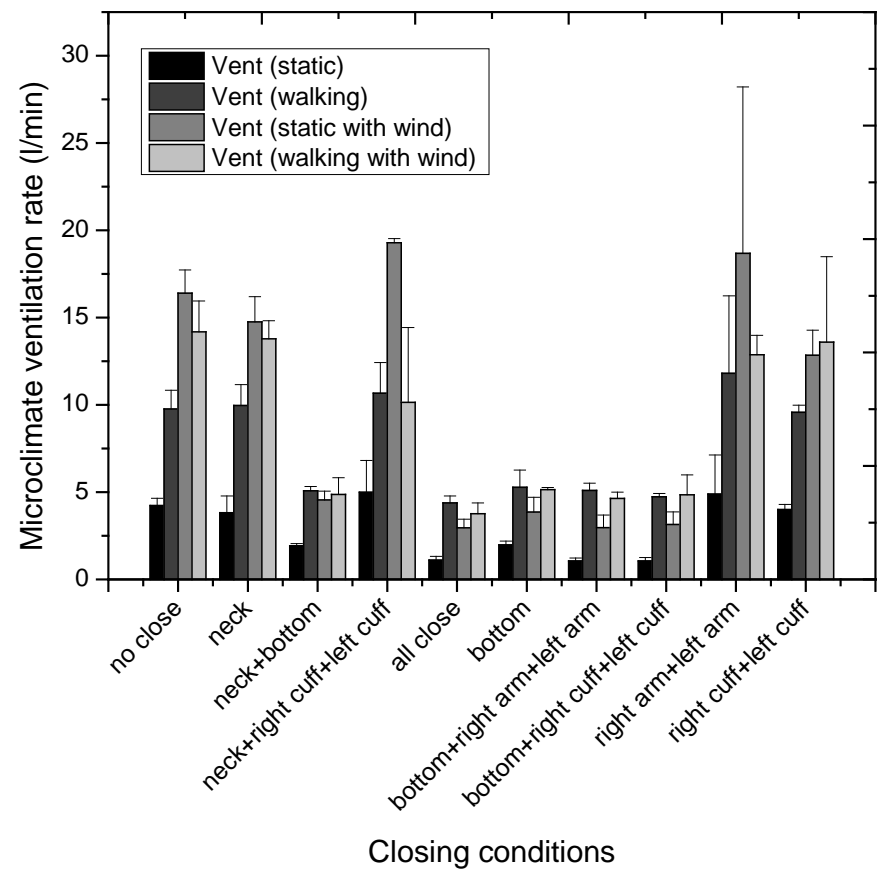

Fig. 7 Observed values of back ventilation with their standard deviation at different conditions of closing single or multiple openings. The horizontal axes subscripts indicate which of the openings were closed.

Three-way (12 closing conditions $\times 2$ walking conditions $\times 2$ wind conditions) Independent ANOVA method was used to do data analysis, by SPSS,version17.0. There were significant 
main effects $(\mathrm{P}<0.001)$ of closing conditions, walking conditions and wind conditions on right arm ventilation rates(figure 6 ). Right arm ventilation of 12closing conditions $(\mathrm{p}<0.05), 2$ walking conditions $(\mathrm{p}<0.001)$ and 2 wind conditions $(\mathrm{p}<0.001)$ also differed significantly. Both walking and wind increased ventilation, walking causing the biggest increase for the arm ventilation.

For the right arm, ventilation rates of static conditions(figure 5), i.e. baseline ventilation values were: no close, 1.4l/min; closing right arm \& right cuff, $1.1 \mathrm{l} / \mathrm{min}$. Ventilation decreased most when closing right arm or right cuff $(0.1 \mathrm{l} / \mathrm{min})$

For ventilation of walking conditions, baseline ventilation values were: no close, $4.51 / \mathrm{min}$; closing right arm \& right cuff, 1.5l/min. Ventilation decreased most (2.51/min, 55.6\%) when closing right arm. It decreased $1.8 \mathrm{l} / \mathrm{min}(40 \%)$ when closing bottom. Ventilation rates when closing neck \& bottom and bottom \& cuffs were almost the same as closing bottom only condition's.

For ventilation with wind, baseline ventilation values were: no close, $4.41 / \mathrm{min}$; closing right arm \& right cuff, $1.5 \mathrm{l} / \mathrm{min}$. Ventilation changes of this situation was different from that of walking condition. Ventilation decreased most (2l/min, 45.5\%) when closing bottom or right arm. It decreased 1.3l/min (29.5\%) when closing cuffs or only right cuff. Compared with the ventilation rate when closing bottom, ventilation rate when closing bottom \& cuffs was 0.81/min less (33.3\%).

For ventilation of walking with wind conditions, baseline ventilation rates were: no close, 9.9l/min; all close, 1.9l/min. Ventilation decreased 6.7l/min (67.8\%) when closing right arm. It decreased 6.6l/min (66.7\%) when closing bottom. Ventilation decreased 0.8l/min (24.2\%) when closing bottom \& cuffs compared with ventilation when closing bottom(3.31/min).

Therefore for the right arm, it appears that the main air exchange pathway was through the bottom aperture of the jacket at all conditions. And there was also part of air exchange through cuffs at wind and walking with wind conditions.

\subsection{Local ventilation rates of chest at different closing and conditions}

Figure 6 illustrated the chest ventilation at different conditions. The error bars of the chest ventilation were relatively larger when there was wind. The reason may be that the interactions of the head-on wind and the aperture closing process caused the complicated microclimate conditions of the chest. Three-way (10 closing conditions $\times 2$ walking conditions $\times 2$ wind conditions) independent ANOVA was used to analyze the chest ventilation. All three factors affected chest ventilation significantly $(\mathrm{p}<0.001)$ except walking conditions ( $\mathrm{p}=0.098$ ). Chest ventilation rates were largest at walking with wind conditions, following by wind conditions. Chest ventilation at walking conditions was the smallest. This may be related to the experimental garment, as it has a stand up collar and the bottom was semi-closed with rubber band. Therefore, the pumping effect(Nunneley and Iimarinen, 1989; Havenith and Nilsson, 2005)only had a limited effect on the chest ventilation. The pressure changes in the chest area may have been smaller in walking than for the arm, leading to less pumping impact of the walking movement.

For chest ventilation at static conditions, two ventilation rates were set as baseline values: no close,10.9l/min; closing neck \& bottom \& right arm \& left arm (all close), 2.01/min. Chest still had air exchange when closing all openings and part connections. The reason was that 
there still occurred air exchange between chest and back as we didn't separate the two parts. Of conditions that only closed one aperture, ventilation reduced most (6.5l/min, 59.6\%) when closing the garment bottom. While it reduced $0.61 / \mathrm{min}(5.5 \%)$ when closing neck, $0.41 / \mathrm{min}(3.7 \%)$ when closing cuffs. It seems an anomaly that only $0.2 \mathrm{l} / \mathrm{min}$ of ventilation reduction was observed when closing the arms. The explanation was that the experimental garment was pulled up when closing the arms with elastic band, which increased air exchange through bottom. This can also be explained from the results when closing bottom and arms.

For ventilation at walking conditions, baseline ventilations were: no close, $6.11 / \mathrm{min}$; all close, 4l/min. 4l/min air exchange still happened when closing all garment apertures. The reason was that it was not possible to completely close the garment bottom when walking, which increased air exchange through the bottom. Ventilation also decreased most (1.6l/min, 21.3\%) when closing bottom. Ventilation increased when closing neck and neck\&arms. The reason may be that closing changed the direction of air exchange, or the garment was pulled up when closing neck as it slipped easily. Compared with closing the bottom condition, ventilation decreased when closing neck\&bottom. While there was almost no change when closing bottom\&arms. Thus when walking without wind, the main air exchange way is through neck\&bottom.

For chest ventilation at $1.2 \mathrm{~m} / \mathrm{s}$ conditions, the baseline ventilation values were: no close, 27.71/min; all close, 7.21/min. Ventilation when closing neck\&bottom and bottom\&cuffs were almost the same to ventilation when closing bottom only.

For chest ventilation at walking with wind conditions, the baseline ventilation values were: no close, $29.31 / \mathrm{min}$; all close, $5 \mathrm{l} / \mathrm{min}$. Compared to ventilation rate $(6.91 / \mathrm{min})$ when closing bottom, ventilation decreased obviously when closing bottom\&cuffs.

Therefore, it can be concluded that for chest the main stream is also through garment bottom. At walking conditions, some air exchange still happened through neck. And part of air also exchanged through cuffs at walking with wind conditions.

\subsection{Local ventilation rates of back at different closing and conditions}

Figure 7 shows back ventilation at different closing, walking and wind conditions. Local ventilation results were analyzed using a three-way(10 closing conditions $\times 2$ walking conditions $\times 2$ wind conditions) independent ANOVA. All three factors (closing conditions, $\mathrm{p}<0.001$, walking conditions, $\mathrm{p}<0.05$, wind conditions, $\mathrm{p}<0.001$ ) were statistically significant. Multi-comparison results showed that all closing conditions differed significantly $(\mathrm{p}<0.05)$ except no close and closing neck $(\mathrm{p}=0.662)$. Both wind and walking increased back ventilation, while the interaction of the two factors decreased ventilation $(12 \%$ on average)compared with back ventilation at wind conditions.

For back ventilation at static conditions, baseline ventilation values were: no close, $4.2 \mathrm{l} / \mathrm{min}$; closing neck \& bottom \& right arm \& left arm (all close), 1.11/min. Ventilation decreased 2.21/min (52.4\%) when closing garment bottom. Ventilation decreased $45 \%$ when closing bottom \& cuffs compared with the situation when only closing bottom.

For back ventilation at walking conditions, baseline ventilation values were: no close, 9.81/min; all close, 4.41/min. Ventilation decreased 4.51/min(45.9\%) when closing bottom. While ventilation changed slightly when closing bottom\&cuffs and bottom\&neck compare with closing bottom situation. 
For back ventilation at wind conditions, baseline values were: no close, $16.4 \mathrm{l} / \mathrm{min}$; all close, 3.01/min. When closing bottom, ventilation decreased $12.5 \mathrm{l} / \mathrm{min}(76.2 \%)$. When closing bottom and cuffs, ventilation decreased almost 25\% compared with the situation when only closing bottom.

For back ventilation of walking at $1.2 \mathrm{~m} / \mathrm{s}$ conditions, baseline ventilation values were: no close, 14.21/min; all close, 3.81/min. Ventilation decreased 9.11/min(64.1\%) when closing bottom. There were no obvious changes when closing neck\&bottom and cuffs\&bottom compared with closing bottom only situation.

Main air exchange of back was still through bottom. For all conditions except walking, some part of air exchange was also through cuffs. Obvious air exchange happened through neck at walking at $1.2 \mathrm{~m} / \mathrm{s}$ conditions.

\subsection{Ventilation rates comparison of three locations at different conditions}

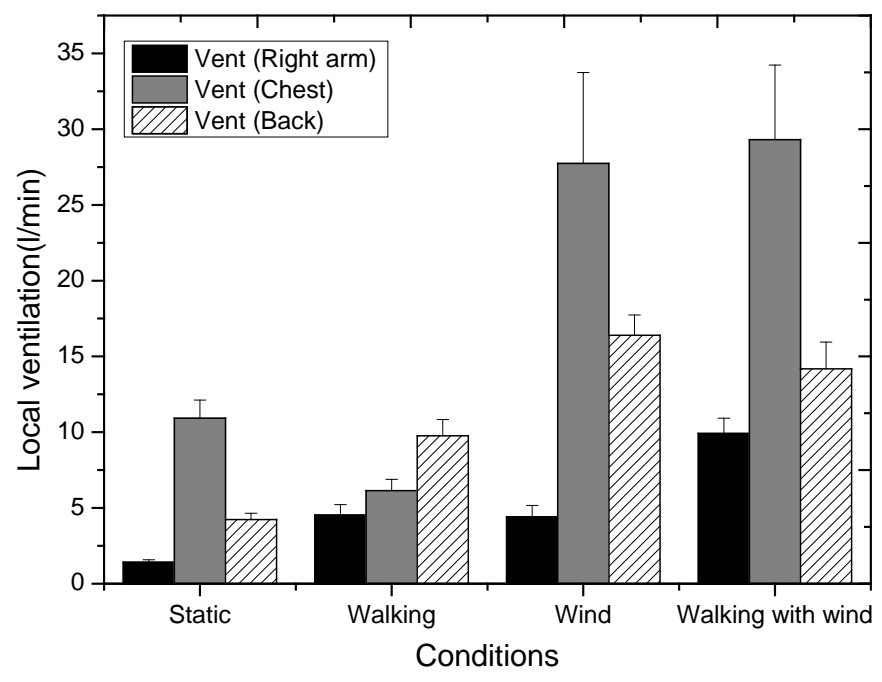

Fig. 8 Local ventilation rates with their standard deviation of three locations in different wind or walking conditions.

Figure 8 shows local ventilation of the right arm, the chest and the back in different conditions(static, walking, wind, walking with wind)without any close condition. Ventilation rates of the three areas were different in different conditions. Ventilation rates of the chest were biggest of the three areas except for walking conditions. The back was the second highest ventilated area, except for walking where it was highest. The arm had the lowest ventilation at all times.

Ventilation rates of all parts were smallest in static conditions, and were biggest in walking with wind conditions except for the back. For the back, the biggest ventilation rate was in the wind only condition, though the difference with walking + wind was minimal. A possible reason may be that the headwind may build a bigger local microclimate space for the back. It is obvious and has already been proved that wind increased ventilation rates(Parsons et al., 1999). Also in this experiment impacts of wind on local microclimate ventilation rates were bigger than those of walking, as shown in figure 8 . 


\section{Conclusions}

A device to evaluate local clothing ventilation rates in different parts of the clothing microclimate of a jacket (right arm, chest and back) was developed. It can measure local clothing ventilation rates at different locations simultaneously. Observed local ventilation rates were different at different locations and in different conditions(static, wind, walking, walking with wind).

Different ventilation rates when closing different garment apertures were monitored and analyzed. For the experimental jacket, chest ventilation rates were largest except in walking conditions.

Ventilation mechanisms/pathways were different at different locations and conditions. Therefore, it is of vital importance to measure regional ventilation during studies of ventilation. It was found that the main air exchange pathway of the three studied locations was through the garment bottom. This may give some suggestions to fashion designers when designing special clothing that can only have one aperture.

\section{Acknowledgement}

We acknowledge the support of Loughborough Design School for this study, in particular the technical support received by Dr Simon Hodder. The authors of the first affiliation express their gratitude to the financial support of the National Natural Science Foundation(51106022), Innovation Program of Shanghai Municipal Education Commission (12ZZ068),Shanghai Pujiang Program and MOC Project of Culture and Art Sciences (12DG36).

\section{References}

Crockford, G.W., Crowder, M., Prestidg, S.P., 1972. Trace gas technique for meauring clothing microclimate air exchange rates. Br. J. Ind. Med. 29, 378-386.

Ghaddar, N., Ghali, K., Jones, B. 2003. Integrated human-clothing system model for estimating the effect of walking on clothing insulation. Int. J. Therm. Sci. 42, 605-619.

Havenith, G., Fogarty, A., Bartlett, R., Smith, C., Ventenat, V. 2008. Male and female upper body sweat distribution during running measured with technical absorbents. Eur. J. Appl. Physiol. 104, 245-255.

Havenith, G., Heus, R., Lotens, W.A. 1990a. Clothing ventilation, vapour resistance and permeability index: changes due to posture, movement and wind. Ergonomics. 33, 989-1005.

Havenith, G., Heus, R., Lotens, W.A. 1990b. Resultant clothing insulation - a function of body movement, posture, wind, clothing fit and ensemble. Ergonomics. 33, 67-84.

Havenith, G., Hiroyuki, U., Hayet, S., Yoshimitsu, I. 2003. Required clothing ventilation for different body regions in relation to local sweat rates. In: Proceedings 2nd European Conference on Protective Clothing (ECPC), "Challenges for Protective Clothing", Montreux, Switzerland, pp. 212-217.

Havenith, G., Nilsson, H. 2005. Correction of clothing insulation for movement and wind effects, a meta-analysis. Eur. J. Appl. Physiol. 93, 636-640.

Havenith, G., Zhang, P., Hatcher, K., Daanen, H. 2010. Comparison of two tracer gas dilution methods for the determination of clothing ventilation and of vapour resistance. Ergon. 53, 548-558.

Lee, Y., Hong, K., Hong. S.A. 2007. 3D quantification of microclimate volume in layered clothing for the prediction of clothing insulation Appl. Ergon. 38, 349-355. 
Lotens, W.A., Havenith, G. 1988. Ventilation of rainwear determined by a trace gas method. Envir. Ergon. 162-175.

Lotens, W.A., Havenith, G. 1991. Calculation of clothing insulation and vapour resistance. Ergon. 34, 233-254.

Nunneley, S., Iimarinen, R. 1989. Heat-stress in protective clothing-interactions among physical and physiological factors. Scand. J. Work. Env. Hea. 15. 52-57.

Parsons, K., Havenith, G., Holmer, I., Nilsson, H., Malchaire, J. 1999. The effects of wind and human movement on the heat and vapour transfer properties of clothing. Ann. Occup. Hyg. 43, 347-352.

Reischl, U., Stransky, A. 1980. Assessment of ventilation characteristics of standard and prototype fire-fighter protective clothing. Text. Res. J. 50, 193-201.

Satsumoto, Y., Havenith, G. 2010. Evaluation of overall and local ventilation in diapers. Text. Res. J. 80, 1859-1871.

Smith, C., Havenith, G. 2011. Body mapping of sweating patterns in male athletes in mild exercise-induced hyperthermia. Eur. J. Appl. Physiol. 111, 1391-1404.

Ueda, H., Havenith, G. 2002. The effect of fabric air permeability on clothing ventilation. In: 10th international Conference on Environmental Ergonomics, Fukuoka, Japan, pp. 621-640.

Ueda, H., Inoue, Y., Havenith, G. 2005. The influence of a back opening on clothing ventilation in rainwear. In: The 11th International Conference On Environmental Ergonomics, Ystad, Sweden, pp. 411-415.

Ueda, H., Inoue, Y., Matsudaira, M., Araki, T., Havenith, G. 2006. Regional microclimate humidity of clothing during light work as a result of the interaction between local sweat production and ventilation. Int. J. Cloth. Sci. Tech. 18, 225-234.

Satsumoto, Y., et al. 2008. Development of device to evaluate the ventilation of diaper. In: Proceedings of Korea-Japan Joint Symposium on Human-Environment Syetem, ChejuKorea.

Zhang, Z., Wang, Y., Li, J. 2010. Mathematical simulation and experimental measurement of clothing surface temperature under different sized air gaps. Fiber. Polym. 11, 911-916. 